\title{
The Influence of Precipitation and Consecutive Dry Days on Burned Areas in Yunnan Province, Southwestern China
}

\author{
Feng Chen, ${ }^{1}$ Zhaofei Fan, ${ }^{2}$ Shukui Niu, ${ }^{1}$ and Jingming Zheng ${ }^{1}$ \\ ${ }^{1}$ College of Forestry, Beijing Forestry University, Beijing 100083, China \\ ${ }^{2}$ Department of Forestry, College of Forest Resources, Mississippi State University, Oktibbeha County, MS 39762, USA
}

Correspondence should be addressed to Shukui Niu; niushukui@bjfu.edu.cn

Received 28 January 2014; Revised 4 April 2014; Accepted 16 April 2014; Published 18 May 2014

Academic Editor: Hann-Ming H. Juang

Copyright (C) 2014 Feng Chen et al. This is an open access article distributed under the Creative Commons Attribution License, which permits unrestricted use, distribution, and reproduction in any medium, provided the original work is properly cited.

\begin{abstract}
Precipitation is among the more limiting meteorological factors affecting the occurrence and extent of forest fire. We examined the correlation between burned area of individual wildfires and the rainfall amounts occurring on the day of the burn and the number of consecutive dry days for a range of limiting daily rainfall amounts $(0-6 \mathrm{~mm})$ used to define a "dry" day. Daily threshold rainfall levels that most significantly affected area burned were determined for each ecoregion in Yunnan province, a major fire-prone area, in southwestern China. Results showed that the burned area of a wildfire decreased exponentially with increasing rainfall amounts on the day of burning. Burned area was also positively correlated to the number of consecutive dry days prior to burning. The threshold rainfall value providing the highest correlation between burned area and the number of consecutive dry days prior to a burn varied between ecoregions. Consecutive dry days with rainfall less than the specified threshold predominantly affected large fires (>100 ha) rather than more frequently occurring small fires. These results will help forest managers evaluate regionalfire danger indices for forest fire prevention, particularly for catastrophic forest wildfires causing significant economic losses and threats to human life and environment.
\end{abstract}

\section{Introduction}

A striking increase in the number and burned area of wildfires has been reported during the past several decades in many regions of the world [1-4]. The number and extent of wildfires in a region are driven by many factors including weather conditions [5], human activities [6], fuel characteristics [7-9], fire management activities [10, 11], land use changes [12], and climatic change [13-15]. Of these factors, climatic variability has been considered to be one of the major determinants of the occurrence and burned area of wildfires, particularly large fires. The effect of climate variability on wildfire occurrence and burned area remains poorly understood and difficult to predict especially under various scenarios of global climate change.

On decadal scales, climatic variability regulates the compositional and structural characteristics of the vegetation such as species populations and their drought tolerance [16] and biomass (fuel) continuity [17] and thus affecting fire regime. On interannual and shorter temporal scales, climate variability affects the flammability of live and dead forest vegetation which may change wildfire behavior $[18,19]$. Previous studies have demonstrated that large-scale climate patterns related to the Pacific decadal oscillation and intense El Niño/La Niña events were more closely linked with the frequency and extent of wildfires [20, 21]. Fire severities in a given fire season were reported to be related to ocean surface temperature anomalies [22] and the Palmer drought severity index (PDSI) [5, 23]. Increases of fire occurrences in Northern Rockiesforests have been shown to be strongly associated with increased spring and summer temperatures and an earlier spring snowmelt [24]. An increase in burned area across Canada from the 1920s to 1990s was correlated with regional warming trends [25]. Both satellite dataand the Russian Federal Forest Service data showed an increase in the area burned in Russia coincided with the current warming trends and extended fire seasons, as well as with predictions of fire regime change [26]. Valendik [27] and 
Lelyakin et al. [28] also suggested that forest fire was expected to occur more frequently in boreal Asiaas a result of increased mean temperature.

Regional climate patterns and local weather conditions clearly play a critical role in setting conditions favorable for forest fire occurrences, and their effect on a particular fire can be inferred from antecedent climate and weather conditions at the time when a fire occurs [29]. Prolonged periods with high temperatures and no rain correlate well with periods of high forest fire danger. Prevailing dry conditions particularly affect the flammability of dead forest fuels. In the Daxinganling forest region of China, forest fires ignited by lighting mostly occur under conditions of dry thunderstorms producing little precipitation, since precipitation levels $<1 \mathrm{~mm}$ have almost no effect on fuel moisture content [30]. The longer the period of consecutive dry days (days without rainfall or with rainfall less than some threshold value), the drier the fuel and the more readily the fuels burn [31]. A period of 3 to 5 consecutive dry days can greatly increase ignition probabilities, 7 to 10 consecutive dry days markedly increases fire spread probabilities, and the risk of catastrophic forest fire occurrence increases greatly with $>15$ consecutive dry days [32].

The likelihood of large fires, therefore, increases during extreme weather conditions (e.g., a long dry period). Venäläinen et al. [33] estimated that at any location in Finland approximately once every ten years a 40 -day period with at most $10 \mathrm{~mm}$ of accumulated rain will occur, and these extreme dry conditions will triple the number of fire occurrences including large fires during a fire season. Prolonged dry weather conditions (about 40 days without precipitation) can sufficiently dry live fuels and larger dead fuels to the point of carrying large, intense fires once they are ignited in the subalpine forest types. Variation in area burned per fire has been shown to be highly correlated with the moisture content of 100-hour $(2.5-7.6 \mathrm{~cm}$ diameter) and 1000-hour $(>7.6 \mathrm{~cm}$ diameter) dead fuels [34]. Once fuels reached critically dry moisture levels late in the season, the spatial pattern of the large, severe stand replacing fires is controlled by weather (wind direction and velocity), not by fuels, stand age, or firefighting activities $[35,36]$. Variation in fuel abundance and topography (including formidable barriers such as the canyon, rivers, and roads) had little influence on the severity or direction of the fire when fuel moistures were critically low [34]. As global warming and climate change related drought events become more frequent and severe regionally and globally, the frequency and burned area of forest fires, especially large, severe, fires tend to increase correspondently [1].

Yunnan province is a major forested area with complex, rich forest resources in the southwest China. The province has experienced a large number of wildfires that caused enormous losses in terms of forest resources, human lives, and economic disruptions [37]. The death toll averages over one hundred persons per year and the average economic loss directly related to forest wildfires reached over ten million US dollars annually during the past decade [37]. Due to extensive areas dominated by flammable forest species, forest fires causing serious damage occur frequently, and fire prevention is becoming quite difficult [38]. Preliminary analyses of historical fire and weather/climate data indicate the daily precipitation and distribution throughout the fire season are an important determinant of forest fire occurrence, particularly the occurrence of large, damaging fires $[39,40]$. The major objective of this study, therefore, is to quantify the relationship between precipitation and burned area of individual fires, and how this relationship may vary by ecoregion, based on historic fire data and observed precipitation data from local weather stations. We hypothesize that the size of a fire occurring on any given day will be correlated with the amount of rainfall on that day. We also predict the number of consecutive dry days with rainfall below a threshold value will be correlated with the burned area of large fires. Specifically, we will test (1) whether the distribution of area burned is different between days where precipitation occurs and dry days, (2) how area burned changes with rainfall on the days prior to fire occurrence, and (3) how the threshold precipitation values best correlated with area burned varies by ecoregion. Answers to these questions will have significant implications in fire severity forecasting and fire prevention in the region.

\section{Materials and Methods}

2.1. Study Area. Yunnan province is located in the southwestern area of China $\left(21^{\circ} 9^{\prime}-29^{\circ} 15^{\prime} \mathrm{N}, 97^{\circ} 30^{\prime}-106^{\circ} \mathrm{E}\right.$, Figure 1$)$. The topography of the province is diverse and includes flat valley bottoms and steep mountains. General elevation ranges from approximately $4000 \mathrm{~m}$ in the northwest to less than $1000 \mathrm{~m}$ in the southeast. The region has a plateau monsoon climate characterized by moderately hot, humid summers and warm, dry winters. Mean annual air temperature averages $14-16^{\circ} \mathrm{C}$, with mean temperatures of $6-8^{\circ} \mathrm{C}$ in January and $19-22^{\circ} \mathrm{C}$ in July. Winter prevails dry continental monsoon, while summer prevails wet marine monsoon, so the distribution of precipitation in the season is very uneven. Annual rainfall averages $1100 \mathrm{~mm}$, and dry season extends from November to April, accounting for only $10-20 \%$ of annual precipitation. Rainy season extends from May to October, and most precipitation is 6-8 for three months, accounting for about $60 \%$ of annual precipitation (Figure 2). From north to south there is a gradient of increasing temperature, precipitation, and humidity (Table 1).

Due to the influence of tropical monsoons from the south and the decrease in altitude from north to south, Yunnan has highly diverse vegetation types ranging from alpine meadows and montane and subalpine temperate forests at higher altitudes to subtropical forests and tropical rainforests at lower altitudes. Broad-leaved species dominate forests in the southwestern portion of the province, while most other areas are dominated by coniferous forests which cover an area of approximately 4.53 million hectares and account for $48.6 \%$ of the province's forested area. The main vegetation types that are prone to forest fires are forests and woodlands dominated by Yunnan pine (Pinus yunnanensis Franch). These natural coniferous forests, along with plantations planted in recent 


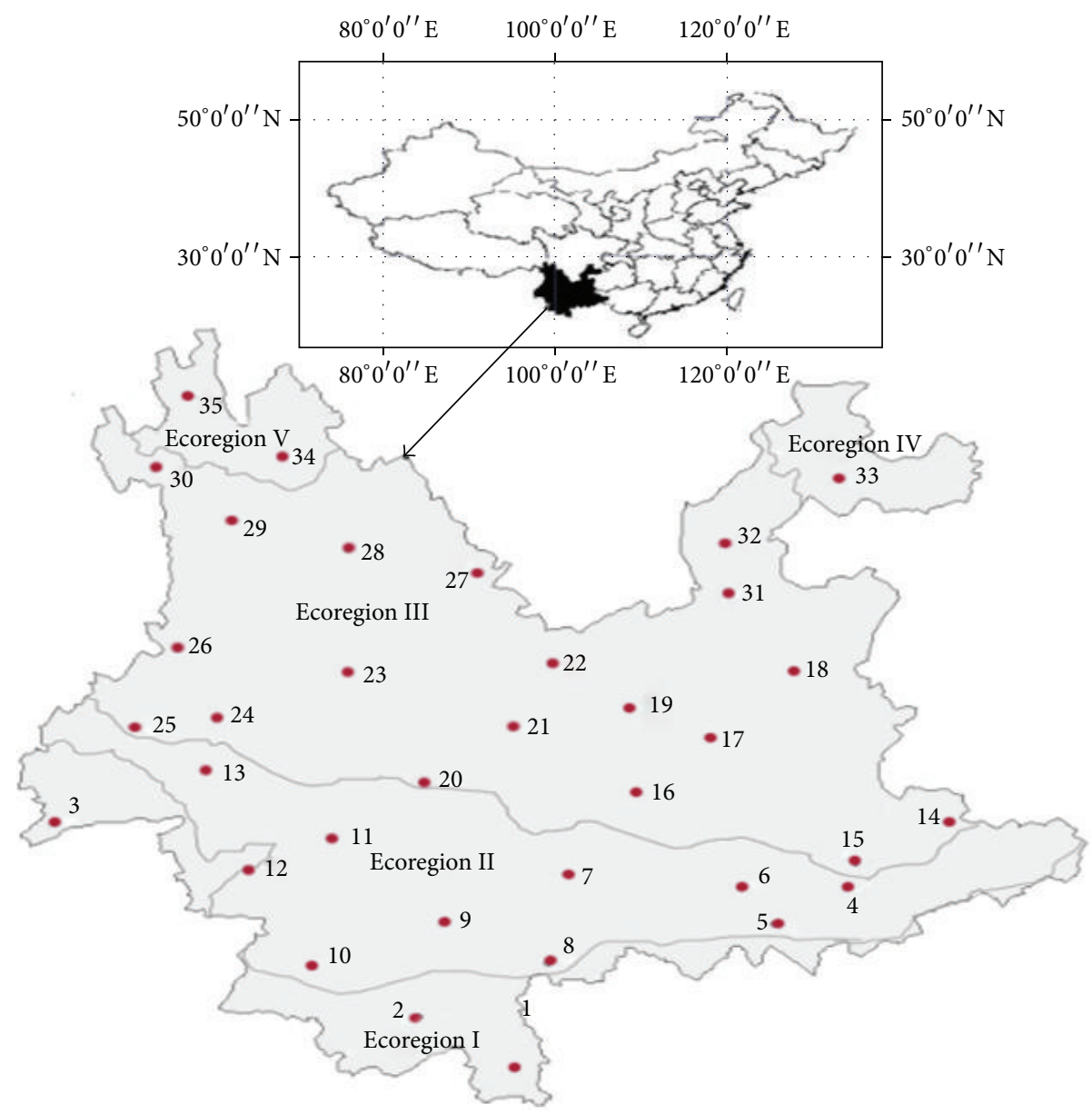

Figure 1: Location of the study area in Yunnan province, southwestern China. The red dots mark the locations of the observation stations with meteorological data for five ecoregions.

years, are highly flammable and susceptible to varying fire ignition sources.

The study area includes five ecoregions, reflecting the spatial heterogeneity in climate, vegetation types, and topography (Table 1). Mountainous ecoregions (VI and V) have a cold and dry climate, while the lower elevation ecoregions (I, II, and III) are characterized by warmer, more humid climates. The higher-elevation ecoregions to the north have higher proportions of coniferous forests, while the lowerelevation ecoregions in the south have higher proportions of evergreen broad-leaved forest.

Ecoregion I has a tropical monsoon climate with higher temperature and abundant precipitation. The ecoregion is frost-free throughout the year; and the area has distinct wet and dry seasons, with precipitation in rainy season (May to October) accounting for $80 \%-90 \%$ of total annual precipitation. This ecoregion has a higher proportion of forest than the other ecoregions, and the vegetation types are tropical seasonal rainforest, evergreen monsoon forest, and mountain rainforest dominated by Pometia pinnata J. $R$. et G. Frost., Parashorea chinensis Wang Hsie, and Lannea coromandelica (Houtt.) Merr.
Ecoregions II and III have similar landform and climate. They have a plateau and subtropical climate, with mildseasonal temperatures and moderate precipitation. There is, however, an obvious difference in vegetation types. Ecoregion II is covered by monsoon evergreen broad-leaved forests dominated by Schima wallichii Choisy, Castanopsis delavayi Franch, and small areas of Pinus kesiya Royle ex Gordon forest, while ecoregion III is dominated by evergreen Quercus Linn. forests and large areas of Pinus yunnanensis Franchmixed with shrubs and grasslands.

Ecoregion IV has a plateau and subtropical climate, but with lower temperatures and less precipitation than ecoregions II and III. The area also has a lower percent forest cover which is dominated by evergreen Quercus semecarpifolia Smith, Cyclobalanopsis glauca (Thunb.) Oerst forest, and some Pinus yunnanensis Franch forest. Ecoregion $\mathrm{V}$ is highest in elevation averaging approximately 4000 meters. The area has a low temperature with a winter snow line elevation of around 5000 meters. Annual precipitation averages $600-700 \mathrm{~mm}$, with dry season rainfall accounting for $10-20 \%$ of annual precipitation. Vegetation types include cold-temperate needle-leaf forest dominated by Picea 


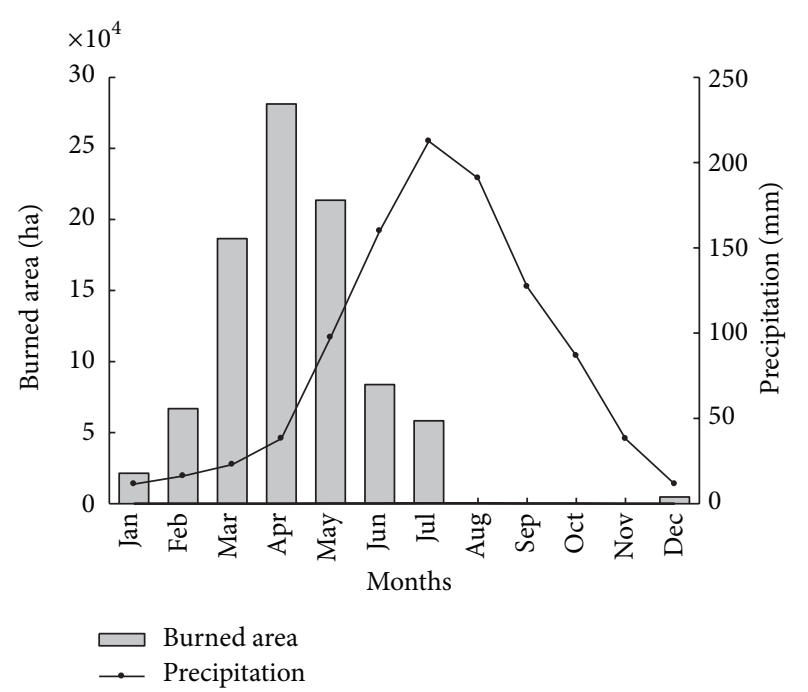

FIGURE 2: The mean annual burned area (ha) and precipitation (mm) during 1996-2008 by month in Yunnan province.

asperata Mast., Abies fabri (Mast.) Craib, and Pinus densata Mast.intermixed with alpine meadow.

2.2. Climate and Fire Data. The fire season in Yunnan province extends from December to May with wildfires mainly occurring from mid-February to mid-May (Figure 2). Human-caused surface fires account for over 95\% of total fires. Crown fires are rare and mostly occurred in young coniferous forests. From 1996 to 2008, in total 7,926 forest fires $(135,788$ ha in total) were reported in Yunnan. For each fire, the date, starting and ending times, location, burned area, and vegetation type were recorded by the Forest Fire Prevention Headquarter Office of Yunnan Province. Daily rainfall data during the same period were obtained from 35 meteorological stations of the China meteorological data sharing network (Figure 1). The daily rainfall data for the area were generated by using Daymet [41], which uses regression and digital elevation maps to interpolate data from existing weather stations over complex terrain. In this study, only 1,983 fires occurring in the fire season within the prefectures with observed rainfall data were used for data analysis.

2.3. Data Analysis. To evaluate the effect of precipitation on the distribution of fire size (area burned), forest fires were classified into two groups: with precipitation on the day of the fire $(n=117)$ and without precipitation $(n=$ $1,866)$ on the day of the fire. Since the distribution of burned area takes a negative exponential trend, the log-transformed burned area was used in analysis of variance to compare the difference in mean fire size between these two groups. With the assumption that precipitation may significantly reduce the size of large, catastrophic fires, the ratio of fire sizes at varying percentiles of the two groups (distributions) were computed to analyze the distributional difference in fire size between the two groups.
To further quantify the change of burned area by precipitation levels on a fire day, quantile regression was used to analyze the relationship between precipitation and burned area of a forest fire. Quantile regression has several advantages over traditional (mean based) regression when the response variable (area burned) varies greatly with unequal variance and/or an abnormal distribution by the predictor variable (amount of rainfall here) and when extreme values represented by the conditional quantiles are of interest. Based on the scatter plot of area burned versus rainfall, the nonlinear quintile regression model was specified as

$$
y_{\mathrm{Q}}=a_{\mathrm{Q}} \exp \left(-b_{\mathrm{Q}} x\right)+\varepsilon,
$$

where $y_{\mathrm{Q}}$ is the estimated conditional Q-percentile of area burned given a value of $x$ (rainfall) and $a_{\mathrm{Q}}$ and $b_{\mathrm{Q}}$ are the estimated regression coefficients. Limited by the number of forest fires by ecoregion, a pooled model was constructed for the whole study area based on the algorithm described in Koenker and Park [42].

With daily precipitation data for the period prior to a fire, the number of consecutive dry days was calculated for each of the 1,983 forest fires, with "dry day" being defined as daily rainfall $\leq 0,1,2,3,4,5$, or $6 \mathrm{~mm}$. Spearman's rank correlation analysis was applied to compute the correlation between the number of consecutive dry days (daily rainfall less than a specific value) and the log-transformed burned area of a subsequent forest fire for each ecoregion. The value of daily precipitation defining a dry day which maximized Spearman's rank correlation coefficient and was significantly different from zero based on bootstrapping analysis was specified as the critical value (threshold) influencing burned areas. Furthermore, forest fires within an ecoregion were divided into six size (burned area, in ha) classes: $<1.0$ (small fire), 1.09.9 (moderately small fire), 10.0-49.9 (moderate fire), 50.099.9 (moderately large fire), 100.0-500.0 (large fire), and 5001000 (extremely large fire), and Spearman's rank correlation coefficient was computed between the number of consecutive days with daily precipitation $\leq$ the threshold value and the log-transformed burned areas by fire size class and ecoregion. The effect of threshold precipitation on forest fires in different size classes within an ecoregion may be evaluated based on the change of Spearman's rank correlation coefficients.

\section{Results}

3.1. The Relationship between Burned Area and Rainfall Amount. Area burned followed a negative exponential distribution for forest fires occurring on both rainy days (with precipitation) and dry days (without precipitation) with mean fire size (area burned) of 43.5 ha and 76.3 ha, respectively, but the distribution for the dry day fires was more skewed, having a longer tail (larger, catastrophic fires) (Table 2). Further examination of the ratio of the percentiles of burned area on rainy days versus on dry days indicated that the burned area of $90 \%$ of the fires occurring on rainy days mostly was 0.5 to 0.8 times large as those occurring on dry days, and among the largest fires (largest 10\%) the burned area on rainy days was less than one tenth large as those occurring on 
TABLE 1: Climate, vegetation, and topography by ecoregion in Yunnan province.

\begin{tabular}{|c|c|c|c|c|c|c|c|}
\hline \multirow{2}{*}{ Ecoregion } & \multirow{2}{*}{ Elevation $(\mathrm{m})$} & \multicolumn{3}{|c|}{ Mean annual temperature $\left({ }^{\circ} \mathrm{C}\right)$} & \multirow{2}{*}{$\begin{array}{l}\text { Mean annual } \\
\text { precipitation }(\mathrm{mm})\end{array}$} & \multirow{2}{*}{ Climatic type } & \multirow{2}{*}{ Vegetation type } \\
\hline & & $T_{\max }$ & $T_{\mathrm{av}}$ & $T_{\min }$ & & & \\
\hline I & $1000-1800$ & 26.3 & 20.6 & 15.2 & $1500-2000$ & Wet & $\begin{array}{l}\text { Tropical seasonal } \\
\text { rainforest }\end{array}$ \\
\hline II & $1500-2000$ & 24.3 & 18.3 & 12.8 & $1000-1600$ & Semiwet & $\begin{array}{l}\text { Monsoon evergreen } \\
\text { broad leaved forest }\end{array}$ \\
\hline III & $1500-3600$ & 21.7 & 15.1 & 10.4 & $1000-1500$ & Semiwet & $\begin{array}{l}\text { Evergreen broad leaved } \\
\text { forest and Pine forest }\end{array}$ \\
\hline IV & 3000 & 18.5 & 12.6 & 7.5 & 760 & Semidry & $\begin{array}{l}\text { Evergreen broad leaved } \\
\text { forest }\end{array}$ \\
\hline $\mathrm{V}$ & 4000 & 16.5 & 10.2 & 5.3 & 700 & Semidry & $\begin{array}{l}\text { Cold-temperate needle } \\
\text { leaf forests meadows }\end{array}$ \\
\hline
\end{tabular}

TABLE 2: Summary statistics of burned areas of forest fires with and without precipitation.

\begin{tabular}{lcc}
\hline & $\begin{array}{c}\text { With precipitation } \\
\text { on a fire day }\end{array}$ & $\begin{array}{c}\text { Without precipitation } \\
\text { on a fire day }\end{array}$ \\
\hline Number of fires & 116 & 1846 \\
Mean fire size (ha) & 43.5 & 76.3 \\
Standard deviation (ha) & 105.6 & 324.3 \\
Mode & 2.0 & 2.0 \\
Skewness & 4.3 & 17.4 \\
Kurtosis & 24.1 & 460.5 \\
0\% minimum & 0.06 & 0.004 \\
$5 \%$ & 0.13 & 0.3 \\
$25 \%$ & 1.3 & 2.3 \\
$50 \%$ median & 5.3 & 8.6 \\
$75 \%$ & 28.3 & 39.3 \\
$90 \%$ & 133.3 & 147.8 \\
$95 \%$ & 266.7 & 300.0 \\
$100 \%$ maximum & 800.0 & 9819.3 \\
\hline
\end{tabular}

dry days (Figure 3(a), Table 2). ANOVA of log-transformed area burned indicated a significant difference between a dry day and a rainy day fire size $(P=0.03)$; however, when the largest $10 \%$ of fires were deleted from both samples, the difference was no longer significant at $\alpha=0.05$. This suggests that precipitation on the same day as a fire occurrence overall has potential to greatly reduce the infrequent, large, catastrophic fires but has a much smaller impact on the size of most frequent, small fires. Quantile regression further quantified the changes in the percentile of areas burned with precipitation on the same day as a fire occurrence (Figure 3(b), Table 3). Based on model statistics, the negative exponential model did a good job of quantifying the effect of precipitation on area burned. Precipitation alone accounted for at least $33 \%$ of variation in areas burned depending on the percentile specified (Table 3 ).

3.2. Correlation between Burned Area and the Number of Consecutive Dry Days prior to a Fire. Spearman's rank correlation analysis suggests that the burned area of a fire was positively correlated with the number of consecutive days with daily precipitation less than a specified threshold value prior to the day of the fire for all ecoregions (Figure 4). Correlation coefficients generally displayed a unimodal distribution which peaked at an ecoregion-specific precipitation value. In ecoregions I and II, the highest correlation (the peak) was only found at $1 \mathrm{~mm}(r=0.29, P<0.01 ; r=0.33, P<$ $0.01)$, the peak in ecoregion III was around $3 \mathrm{~mm}(r=0.31$, $P<0.01)$, and in ecoregion IV and ecoregion $\mathrm{V}$, the peak was located at a precipitation level of around $5 \mathrm{~mm}(r=0.30$, $P<0.01 ; r=0.32, P<0.01$ ) (Figure 4). This suggested that there is a variation in the daily threshold rainfall in defining dry day among five ecoregions due to differences in some aspects such as vegetation and climate by ecoregion, with $1 \mathrm{~mm}$ for ecoregions I and II, $3 \mathrm{~mm}$ for ecoregion III, and $5 \mathrm{~mm}$ for ecoregions IV and V. The daily threshold rainfall in defining dry day has a practical significance for the local forest fire prevention. The number of consecutive dry days can provide fire control managers with reference for measuring fire danger severity which may be useful in planning fire control operations.

3.3. The Impact of Consecutive Dry Days on Different Sizes of Fire. Given the precipitation values (or thresholds) corresponding to the maximum correlation coefficient in each ecoregion, the rank correlation between the number of consecutive days prior to a fire with daily precipitation less than the threshold and burned area of a fire was analyzed for six fire size groups specified in the method, respectively. Within each ecoregion, the correlation coefficient increased rapidly from the small fire group $(<1.0 \mathrm{ha})$ to the moderately large fire group (50.0-99.9 ha) and then maintained a gentle increase across the larger fire size groups (Figure 5). The correlation coefficients for fire sizes $<50$ ha were all less than 0.2 and not significantly different from zero at $\alpha=0.05$, while the correlation was statistically significant for all fire size groups $\geq 50$ ha. This suggests that dry periods prior to burning have a significant influence on the size of large fires ( $\geq 50$ ha) or may more likely cause the increase in fire size into the larger size categories, but not much of an effect on the size of small or moderate fires. 


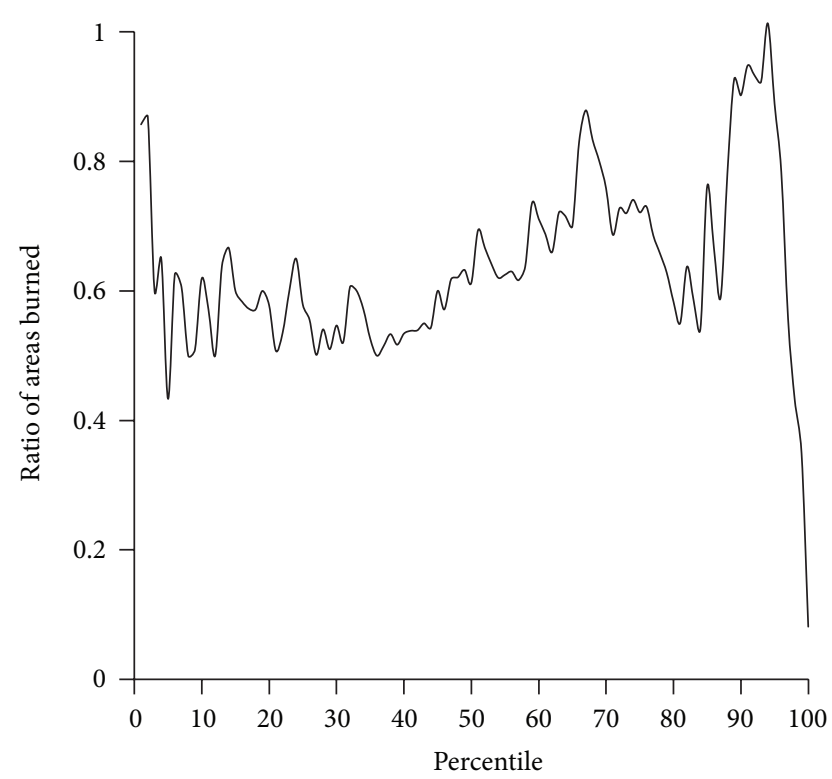

(a)

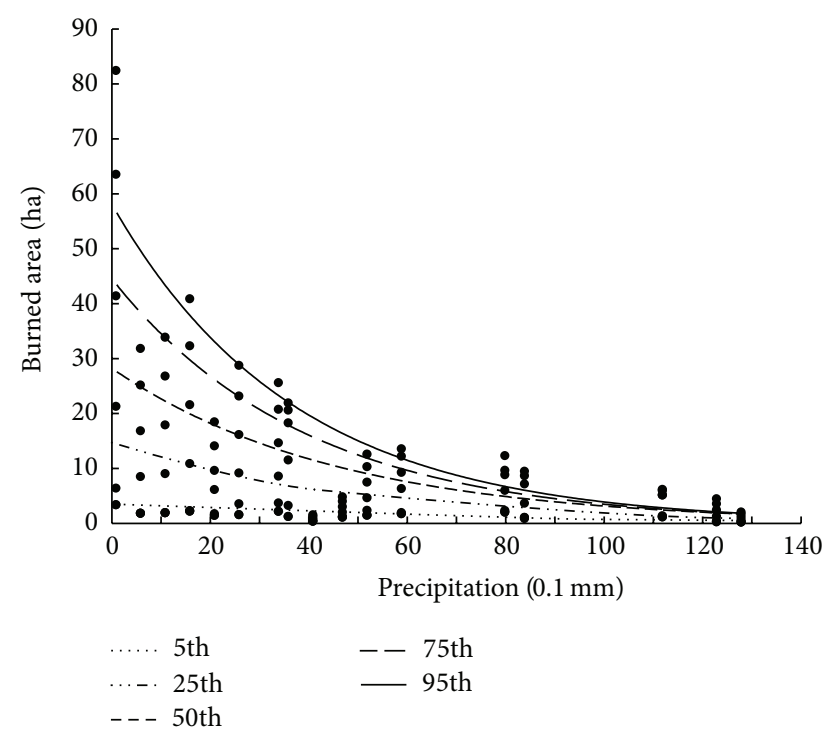

(b)

FIgURE 3: Ratio of the percentiles of burned area with precipitation versus without precipitation on a day of a fire (a) and the relationship between burned area and precipitation (b). Panel (b) shows the change of the percentile (5th, 25th, 50th, 75th, and 95th) lines of burned area generated by quantile regression model (1) with the rainfall amount on a day of burn.

\section{Discussion}

Variability in intensity and timing of precipitation (e.g., daily rainfall amount and the number of consecutive days without rain or with rainfall amounts less than certain thresholds) strongly influence the extent (area burned) of wildfires [39, 43]. Precipitation generally reduces the likelihood of large, catastrophic fires (Table 2). In Yunnan province, for instance, the area burned of the largest fire that occurred on a fire day without precipitation is more than ten times larger than that of a fire on a day with precipitation prior to the fire occurrence. D. X. Viegas and M. T. Viegas [43] reported an exponential relationship between areas burned and total precipitation during fire season. One explanation for the relationship is, presumably, that precipitation increases fuel moisture content thus decrease the potential for fire spread $[44,45]$.

Song et al. [46] used a fire model to simulate the effect of different rainfall probabilities on the frequency-size distribution of forest fires and found that rainfall had a larger impact on large forest fires than on small ones. This is consistent with our study using real fire and precipitation data. As we have shown, area burned is, on average, significantly reduced with an increase in precipitation (Figure 3(b)). As the percentile of area burned increased from $5 \%$ to $95 \%$, the percentile regression lines became steeper, meaning precipitation had a substantial impact on the size (or extent) of larger fires. Based on the fitted equations, one can calculate that the area burned of fires in the 99th percentile would be reduced from around 852 ha (the $a_{\mathrm{Q}}$ coefficient in Table 3 ) at a very small amount of precipitation (e.g., $0.01 \mathrm{~mm}$ ) to $298 \mathrm{ha}$ at $6 \mathrm{~mm}$ of precipitation, a reduction of nearly two-thirds. Similarly, the area burned for the 95th percentile of large fires would be reduced from an average of 57 ha to 51 ha, a decrease of approximately $10 \%$ for the same range of variability in precipitation.

The coefficient $a_{\mathrm{Q}}$ reflects the Qth percentile of the area burned when the precipitation approaches zero (no rain), and the coefficient $b_{Q}$ reflects the rate of reduction in the area burned as the precipitation changes. The larger the $b_{Q}$ is, the lower the rate is. From the regression models in Table 3, precipitation on a fire day is especially effective to reduce the likelihood of large fires (100-499 ha) and extremely large fires ( $\geq 500$ ha) but has a limited effect on reducing the average size of moderate and small fires ( $<100$ ha). Knapp [47], Littell et al. [48], and others have indicated the potential impact of other climatic factors such as temperature and vegetation cover on area burned. Because we lacked the data for constructing more comprehensive quantile regression models, we built a set of models for the entire province. However we recognize that, because of the great variability in temperatures and vegetation composition among ecoregions, distinct ecoregion models should be developed to better quantify the precipitation effect. This would provide better information for decision making on presuppression activities.

Fire occurrence is closely related to meteorological preconditions $[49,50]$. In Yunnan province, the driest months (November and December through February, with mean daily rainfall amounts $<1 \mathrm{~mm}$ ) are followed by the peak fire months (March through May), suggesting a lag effect for periods of little precipitation on fire incidence and extent (Figure 2). The mechanism for this lag effect may be related to the interception storage capacities of forest canopies, ground evaporation, and gradual changes in soil and fuel moisture conditions. Rutter [51] reported interception storage capacities of 1.0 to $2.1 \mathrm{~mm}$ for coniferous forests and $1.0 \mathrm{~mm}$ for deciduous forest in summer. A similar value of $1.3 \mathrm{~mm}$ was found by Simpson et al. [52] for a Douglas-fir forest in western 
TABLE 3: The quintile regression equation of burned areas for different rainfall amounts.

\begin{tabular}{lccccccc}
\hline Quintile & $a_{\mathrm{Q}}$ & S.E. ${ }^{a}$ & $b_{\mathrm{Q}}$ & S.E. $^{b}$ & $R^{2}$ & $P$ & $\begin{array}{c}\text { Predicted burned area (ha) } \\
\text { (95\% confidence interval) }\end{array}$ \\
\hline $1 \%$ & 2.268 & 0.212 & -0.013 & 0.002 & 0.49 & $<0.01$ & $0.18 \sim 2.47$ \\
$5 \%$ & 3.460 & 0.618 & -0.019 & 0.005 & 0.49 & $<0.01$ & $0.23 \sim 3.32$ \\
$25 \%$ & 15.732 & 1.172 & -0.017 & 0.006 & 0.40 & $<0.01$ & $0.52 \sim 15.02$ \\
$50 \%$ & 29.361 & 2.518 & -0.016 & 0.007 & 0.35 & $<0.01$ & $0.83 \sim 28.67$ \\
$75 \%$ & 43.372 & 3.763 & -0.016 & 0.008 & 0.34 & $<0.01$ & $1.15 \sim 41.16$ \\
$95 \%$ & 57.106 & 5.580 & -0.016 & 0.008 & 0.33 & $<0.01$ & $1.40 \sim 55.28$ \\
$96 \%$ & 386.517 & 8.538 & -0.193 & 0.008 & 0.80 & $<0.01$ & $10.03 \sim 80.29$ \\
$97 \%$ & 526.281 & 9.325 & -0.182 & 0.007 & 0.90 & $<0.01$ & $16.51 \sim 86.53$ \\
$98 \%$ & 758.167 & 10.311 & -0.200 & 0.008 & 0.95 & $<0.01$ & $18.35 \sim 90.61$ \\
$99 \%$ & 851.777 & 12.651 & -0.175 & 0.006 & 0.96 & $<0.01$ & $21.96 \sim 98.49$ \\
\hline
\end{tabular}

S.E. denotes standard error of the parameters.

Washington. Spittlehouse and Black [53] used $3.0 \mathrm{~mm}$ for a Douglas-fir forest in northwest of Courtenay on Vancouver Island, but this value includes some loss due to evaporation. Flannigan and Harrington [39] defined limiting precipitation of $1.5 \mathrm{~mm}$ as a dry day, assuming this value closely to fit the estimates of maximum water holding capacity of various forest canopies. Hall [54] estimated a precipitation threshold of $2 \mathrm{~mm}$ for both shrubs and trees and a value of $1 \mathrm{~mm}$ in grass vegetation, based on an analysis of the difference in precipitation amounts between wildfires associated with lightning and lightning without ignitions. In national fire danger rating system (NERDS) used in the United States, a drought index is calculated based on the number of consecutive days with precipitation $\leq 5.0 \mathrm{~mm}$ [44]. In the Canadian fire danger rating system (CFDRS), the definition of the threshold precipitation for drought was $2.8 \mathrm{~mm}$ [55].

In this study, predryness conditions were estimated by the number of the consecutive dry days with daily rainfall amounts across a range of values $(<0,1,2,3,4,5$, and $6 \mathrm{~mm})$. These measures of "dryness" were correlated, by ecoregion, with area burned of forest fires. The results suggested that there is variation in the threshold rainfall $(1 \mathrm{~mm}$ for ecoregions I and II, $3 \mathrm{~mm}$ for ecoregion III, and $5 \mathrm{~mm}$ for ecoregions IV and V) that was maximally correlated with the area burned. There is a decreasing trend for the threshold rainfall value with an increase in humidity across ecoregions, most likely due to differences in soil moisture content determined by wet conditions across ecoregions (not reported here).

Drought influences forest fire by means of changing fuel moisture content [56]. In arid regions, with perennial drought, lower soil water content typically means that surface fuels are relatively dry. There tends to be a greater difference between fuel moisture content and the moisture of extinction, and subsequently the threshold rainfall value is larger. Conversely, in humid regions, due to more precipitation, soils have consistently higher moisture contents and surface fuel moistures are higher. Consequently, the amount of precipitation needed to raise fuel moisture contents to the moisture of extinction is less and the threshold rainfall value is correspondingly smaller.
This study showed that the number of consecutive days has a greater association with the size of large fires (>100 ha) but has less influence on the size of small fires. This may be explained by the fact that most fires in the study area are caused by humans. Small fires have a greater degree of randomness, largely influenced by human factors, so the correlation between small fires and preconditions of dryness is weaker. Concerning the relationship between environmental conditions and major forest fires, Zhang et al. [57] found a close relationship between the size of major forest fires and consecutive dry days prior to fire occurrence. Brotak and Reifsnyder [58] and Crimmins [59] demonstrated that extended dryness is associated with large fire occurrence, which is often dominated by synoptic weather conditions of dry. Many other studies had shown previous drought to have a significant impact on large fires occurrence, and forecast the probability of large fire events using drought index [6062]. Besides, the dryness of fuel is not only associated with rainfall but also with other meteorological factors and fuel characteristics $[5,7,9]$. In our study, differences in fuel types among ecoregions will inevitably affect the threshold rainfall of burned areas; therefore, whether the conclusion of this study can be applied to other areas requires further research.

\section{Conclusions}

Based on our analysis of the 1996-2008 wildfire records and precipitation data in Yunnan province, southwestern China, the following conclusions were drawn.

(1) The size of a fire is closely associated with the rainfall amounts on the day of the burn. The relationship between burned area and rainfall amounts displayed a significant exponential decay. Large amounts of rainfall have the potential to reduce fire size with increases in fuel moisture contents and slow rates of spread.

(2) Burned area is related to the number of consecutive dry days prior to fire occurrence. The strength of this correlation varies depending on the daily rainfall amount used to define "dry day," reaching a 

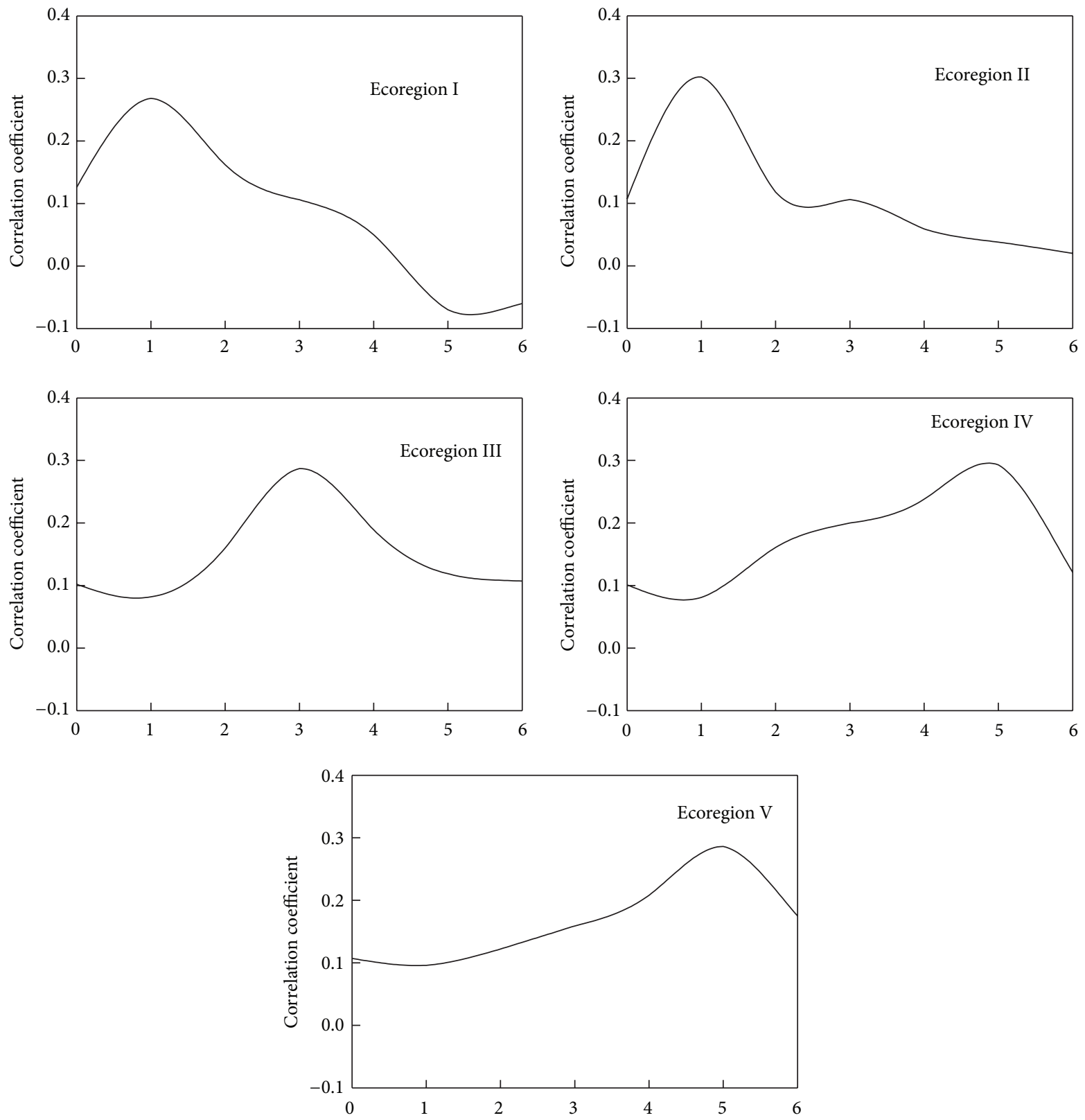

Consecutive dry days with different daily threshold rainfall $(\mathrm{mm})$

FIGURE 4: The change of correlation coefficients between long-transformed burned area and the number of consecutive dry days defined by the threshold daily rainfall amount $(\mathrm{mm})$ by ecoregion.

maximum value at a threshold daily rainfall amount which changes between ecoregions. This suggests that different thresholds of daily rainfall amount should be used to define "dry day" for the ecoregions in Yunnan province.

(3) The increasing trend in correlation between burned area (fire size) and the number of consecutive dry days defined by the identified threshold of daily rainfall amount from the small fire group to large fire group manifests that the threshold of daily rainfall identified for each ecoregion will be useful for presuppression activities of large, severe fires (e.g., > 100 ha). One application will be, among others, evaluating the current fire danger rating system in Yunnan province.

\section{Conflict of Interests}

The authors declare no conflict of interests.

\section{Authors' Contribution}

Feng Chen, Zhaofei Fan, and Shukui Niu contributed equally to this work. 

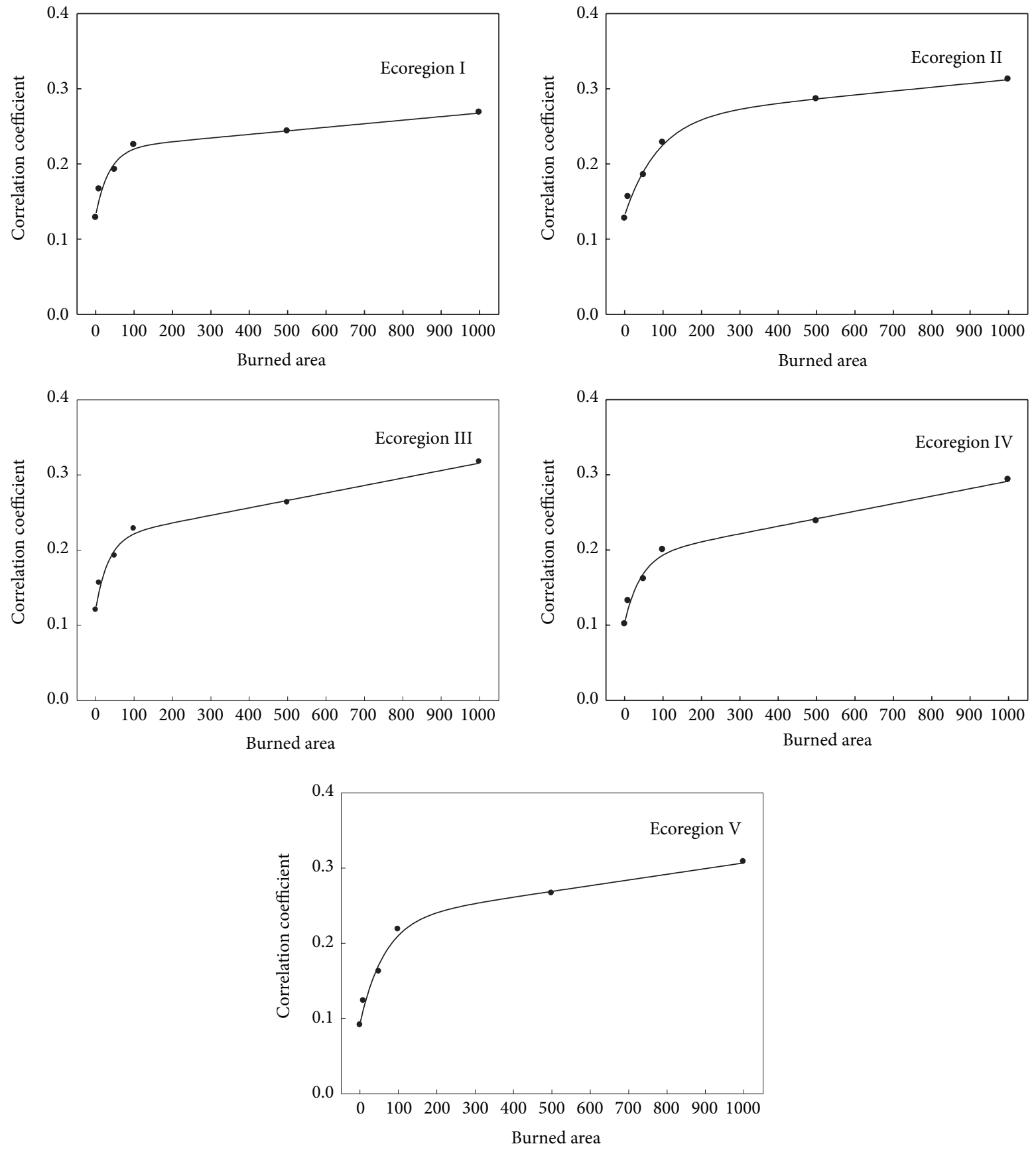

FIGURE 5: The change of correlation coefficients between long-transformed burned area and the number of consecutive dry days defined by the threshold daily rainfall amount $(\mathrm{mm})$ by fire size group and ecoregion. The six fire size classes (represented by black dots) are $<1.0$ (small fire), 1.0-9.9 (moderately small fire), 10.0-49.9 (moderate fire), 50.0-99.9 (moderately large fire), 100.0-500.0 (large fire), and 500-1000 (extremely large fire), respectively.

\section{Acknowledgments}

The authors would like to acknowledge Forest Fire Prevention Headquarter Office of Yunnan Province for providing fire data. Funding for this research was provided by the Forestry Public Welfare Project (200804001), which was initiated by SFA (State Forestry Administration). Dr. Scott D. Roberts from the Department of Forestry, Mississippi State University, and Dr. Michael Crosby from Shorter University reviewed this paper. The authors thank both of them.

\section{References}

[1] T. J. Brown, B. L. Hall, and A. L. Westerling, "The impact of twenty-first century climate change on wildland fire danger in 
the western united states: an applications perspective," Climatic Change, vol. 62, no. 1-3, pp. 365-388, 2004.

[2] European Commission, Forest Fires in Europe-Report No. 4, S.P.I.04.124, Publication of the European Commission, 2004.

[3] M. D. Flannigan, J. B. Stocks, and M. Weber, "Fire regimes and climatic change in Canadian forests," in Fire and Climate Change in Temperate Ecosystems of the Western Americas, T. T. Veblen, L. W. Baker, G. Montenegro et al., Eds., pp. 97-119, Springer, New York, NY, USA, 2003.

[4] B. J. Stocks, M. A. Fosberg, T. J. Lynham et al., "Climate change and forest fire potential in Russian and Canadian boreal forests," Climatic Change, vol. 38, no. 1, pp. 1-13, 1998.

[5] R. C. Balling Jr., G. A. Meyer, and S. G. Wells, "Relation of surface climate and burned area in Yellowstone National Park," Agricultural and Forest Meteorology, vol. 60, no. 3-4, pp. 285293, 1992.

[6] R. Vélez, "High intensity forest fires in the Mediterranean Basin: natural and socioeconomic causes," Disaster Manage, vol. 5, pp. 16-20, 1993.

[7] F. P. Schoenberg, R. Peng, Z. Huang, and P. Rundel, "Detection of non-linearities in the dependence of burn area on fuel age and climatic variables," International Journal of Wildland Fire, vol. 12, no. 1, pp. 1-6, 2003.

[8] M. de Luís, M. F. García-Cano, J. Cortina, J. Raventós, J. C. González-Hidalgo, and J. R. Sánchez, "Climatic trends, disturbances and short-term vegetation dynamics in a Mediterranean shrubland," Forest Ecology and Management, vol. 147, no. 1, pp. 25-37, 2001.

[9] F. Mouillot, S. Rambal, and R. Joffre, "Simulating climate change impacts on fire frequency and vegetation dynamics in a Mediterranean-type ecosystem," Global Change Biology, vol. 8, no. 5, pp. 423-437, 2002.

[10] A. Badia, D. Saurí, R. Cerdan, and J.-C. Llurdés, "Causality and management of forest fires in Mediterranean environments: an example from Catalonia," Environmental Hazards, vol. 4, no. 1, pp. 23-32, 2002.

[11] J. S. Fried, J. K. Gilless, W. J. Riley et al., "Predicting the effect of climate change on wildfire behavior and initial attack success," Climatic Change, vol. 87, no. 1, pp. 251-264, 2008.

[12] F. C. Rego, "Land use changes and forest fires," in Responses of Forest Ecosystems to Environmental Changes, A. Teller, P. Mathy, and J. N. Jeffers, Eds., pp. 367-373, Elsevier, London, UK, 1992.

[13] F. W. Davis and J. Michaelsen, "Sensitivity of fire regime in chaparral ecosystems to climate change," in Global Change and Mediterranean-Type Ecosystems, M. J. Moreno and C. W. Oechel, Eds., pp. 435-456, Springer, New York, NY, USA, 1995.

[14] M. D. Flannigan, B. J. Stocks, and B. M. Wotton, "Climate change and forest fires," Science of the Total Environment, vol. 262, no. 3, pp. 221-229, 2000.

[15] J. S. Fried, M. S. Torn, and E. Mills, “The impact of climate change on wildfire severity: a regional forecast for northern California," Climatic Change, vol. 64, no. 1-2, pp. 169-191, 2004.

[16] N. L. Stephenson, "Climatic control of vegetation distribution: the role of the water balance," American Naturalist, vol. 135, no. 5, pp. 649-670, 1990.

[17] N. L. Stephenson, "Actual evapotranspiration and deficit: biologically meaningful correlates of vegetation distribution across spatial scales," Journal of Biogeography, vol. 25, no. 5, pp. 855870, 1998 .

[18] E. K. Heyerdahl, L. B. Brubaker, and J. K. Agee, "Annual and decadal climate forcing of historical fire regimes in the interior
Pacific Northwest, USA," The Holocene, vol. 12, no. 5, pp. 597604, 2002.

[19] T. T. Veblen, "Historic range of variability of mountain forest ecosystems: concepts and applications," Forestry Chronicle, vol. 79, no. 2, pp. 223-226, 2003.

[20] T. W. Swetnam and J. L. Betancourt, "Fire-southern oscillation relations in the southwestern United States," Science, vol. 249, no. 4972, pp. 1017-1020, 1990.

[21] C. S. Jones, J. F. Shriver, and J. J. O’Brien, “The effects of El Niño on rainfall and fire in Florida," The Florida Geographer, vol. 30, pp. 55-69, 1999.

[22] T. W. Swetnam and J. L. Betancourt, "Mesoscale disturbance and ecological response to decadal climatic variability in the American Southwest," Journal of Climate, vol. 11, no. 12, pp. 3128-3147, 1998.

[23] Y. Chen, J. T. Randerson, D. C. Morton et al., "Forecasting fire season severity in South America using sea surface temperature anomalies," Science, vol. 334, no. 6057, pp. 787-791, 2011.

[24] A. L. Westerling, H. G. Hidalgo, D. R. Cayan, and T. W. Swetnam, "Warming and earlier spring increase Western U.S. forest wildfire activity," Science, vol. 313, no. 5789, pp. 940-943, 2006.

[25] N. P. Gillett, A. J. Weaver, F. W. Zwiers, and M. D. Flannigan, "Detecting the effect of climate change on Canadian forest fires," Geophysical Research Letters, vol. 31, no. 18, Article ID L18211, 2004.

[26] A. J. Soja, N. M. Tchebakova, N. H. F. French et al., "Climateinduced boreal forest change: predictions versus current observations," Global and Planetary Change, vol. 56, no. 3-4, pp. 274296, 2007.

[27] E. N. Valendik, "Temporal and spatial distribution of forest fires in Siberia," in Fire in Ecosystems of Boreal Eurasia, J. G. Goldammer and V. V. Furyaev, Eds., pp. 129-138, Kluwer Academic, Dodrecht, The Netherlands, 1996.

[28] A. L. Lelyakin, A. O. Kokorin, and I. M. Nazarov, "Vulnerability of Russian forests to climate changes. Model estimation of $\mathrm{CO}_{2}$ fluxes," Climatic Change, vol. 36, no. 1-2, pp. 123-133, 1997.

[29] E. D. Reinhardt, R. E. Keane, and J. K. Brown, "First order fire effects model: FOFEM 4.0, user's guide," General Technical Report INT-344, USDA Forest Service, 1997.

[30] X. R. Tian, L. F. Shu, and F. J. Zhao, "Conditions of lighting fires occurrence in Daxinganling forest region," Forestry Science, vol. 48, no. 7, pp. 98-103, 2012 (Chinese).

[31] L. F. Shu, X. R. Tian, and X. J. Kou, "Forest fire research review: forest fire prediction," Forestry Research, vol. 6, no. 4, pp. 34-37, 2003 (Chinese).

[32] Z. J. Song, The Principle of Forest Fire and Forest Fire Forecast, Meteorological Press, Beijing, China, 1991, (Chinese).

[33] A. Venäläinen, K. Jylhä, B. E. Kilpeläinen et al., "Recurrence of heavy precipitation, dry spells and deep snow cover in Finland based on observations," Boreal Environment Research, vol. 14, pp. 166-172, 2009.

[34] M. G. Turner, W. W. Hargrove, R. H. Gardner, and W. H. Romme, "Effects of fire on landscape heterogeneity in Yellowstone National Park, Wyoming," Journal of Vegetation Science, vol. 5, no. 5, pp. 731-742, 1994.

[35] G. W. Minshall, J. T. Brock, and J. D. Varley, "Forest fires and Yellowstone's stream ecosystems," BioScience, vol. 39, no. 10, pp. 707-715, 1989.

[36] R. H. Wakimoto, "National fire management policy: a look at the need for change," Western Wildlands, vol. 15, pp. 35-39, 1989. 
[37] G. Li, "Forest fire causes analysis and management countermeasures in Yunnan province," Forest Fire Prevention, vol. 7, pp. 1011, 2000 (Chinese).

[38] Z. Huo and H. N. Liu, "The characteristics of forest fire in Yunnan province," Forest Fire Prevention, vol. 1, pp. 12-14, 1987 (Chinese).

[39] M. D. Flannigan and J. B. Harrington, "A study of the relation of meteorological variables to monthly provincial area burned by forest fire in Canada 1953-80," Journal of Applied Meteorology, vol. 27, pp. 441-452, 1988.

[40] Z. A. Holden, P. Morgan, M. A. Crimmins, R. K. Steinhorst, and A. M. S. Smith, "Fire season precipitation variability influences fire extent and severity in a large southwestern wilderness area, United States," Geophysical Research Letters, vol. 34, no. 16, Article ID L16708, 2007.

[41] P. E. Thornton, S. W. Running, and M. A. White, "Generating surfaces of daily meteorological variables over large regions of complex terrain," Journal of Hydrology, vol. 190, no. 3-4, pp. 214251, 1997.

[42] R. Koenker and B. J. Park, "An interior point algorithm for nonlinear quantile regression," Journal of Econometrics, vol. 71, no. 1-2, pp. 265-283, 1996.

[43] D. X. Viegas and M. T. Viegas, "A relationship between rainfall and burned area for Portugal," International Journal of Wildland Fire, vol. 4, no. 1, pp. 11-16, 1994.

[44] J. J. Keetch and G. M. Byram, "A drought index for forest fire control," Research Paper SE-38, USDA Forest Service, Southeastern Forest and Range Experiment Station, 1968.

[45] W. C. Bessie and E. A. Johnson, "The relative importance of fuels and weather on fire behavior in subalpine forests," Ecology, vol. 76, no. 3, pp. 747-762, 1995.

[46] W. Song, F. Weicheng, W. Binghong, and Z. Jianjun, "Selforganized criticality of forest fire in China," Ecological Modelling, vol. 145, no. 1, pp. 61-68, 2001.

[47] P. A. Knapp, "Intermountain west lightning-caused firesclimatic predictors of area burned," Journal of Range Management, vol. 48, no. 1, pp. 85-91, 1995.

[48] J. S. Littell, D. Mckenzie, D. L. Peterson, and A. L. Westerling, "Climate and wildfire area burned in western U.S. ecoprovinces, 1916-2003," Ecological Applications, vol. 19, no. 4, pp. 1003-1021, 2009.

[49] K. Finkele, G. A. Mills, G. Beard, and D. A. Jones, "National daily gridded soil moisture deficit and drought factors for use in prediction of forest fire danger index in Australia," Research Report 119, Bureau of Meteorology Research Centre, 2006.

[50] B. L. Hall and J. T. Brown, "A comparison of precipitation and drought indices related to fire activity in the US," in Proceedings of the 5th Symposium on Fire and Forest Meteorology, American Meteorological Society, 2003.

[51] A. J. Rutter, "The hydrological cycle in vegetion," in Vegetation and the Atmosphere, J. L. Monteith, Ed., pp. 111-154, Academic Press, London, UK, 1975.

[52] J. R. Simpson, L. J. Fritschen, and K. E. Saxton, "Adapting an agricultural soil-plant-air-water model for use in forests," in The Forest-Atmosphere Interaction, B. A. Hutchison and B. B. Hicks, Eds., pp. 197-210, Reidel, Dordrecht, The Netherlands, 1985.

[53] D. L. Spittlehouse and T. A. Black, "A growing season water balance model applied to two Douglas fir stands," Water Resources Research, vol. 17, no. 6, pp. 1651-1656, 1981.

[54] B. L. Hall, "Precipitation associated with lightning-ignited wildfires in Arizona and New Mexico," International Journal of Wildland Fire, vol. 16, no. 2, pp. 242-254, 2007.
[55] C. E. van Wagner, "Development and structure of the Canadian forest fire weather index system," Tech. Rep. 35, Canadian Forestry Service, Ottawa, Canada, 1987.

[56] C. E. van Wagner, Structure of the Canadian Forest Fire Weather Index, Canadian Forestry Service, Ottawa, Canada, 1974.

[57] S. Y. Zhang, C. H. Zhu, and H. Chen, "The study of Meteorological elements and major forest fire," Journal of Natural Disasters, vol. 9, no. 2, pp. 111-117, 2000 (Chinese).

[58] E. A. Brotak and W. E. Reifsnyder, "An investigation of the synoptic situations associated with major wildland fires," Journal of Applied Meteorology, vol. 16, no. 9, pp. 867-870, 1977.

[59] M. A. Crimmins, "Synoptic climatology of extreme fire-weather conditions across the southwest United States," International Journal of Climatology, vol. 26, no. 8, pp. 1001-1016, 2006.

[60] H. K. Preisler and A. L. Westerling, "Statistical model for forecasting monthly large wildfire events in western United States," Journal of Applied Meteorology and Climatology, vol. 46, no. 7, pp. 1020-1030, 2007.

[61] H. K. Preisler, A. L. Westerling, K. M. Gebert, F. MunozArriola, and T. P. Holmes, "Spatially explicit forecasts of large wildland fire probability and suppression costs for California," International Journal of Wildland Fire, vol. 20, no. 4, pp. 508-517, 2011.

[62] T. P. Holmes, R. J. Huggett Jr., and A. L. Westerling, "Statistical analysis of large forest fires," in The Economics of Forest Disturbances, T. P. Holmes, R. J. Huggett Jr., and J. M. Pye, Eds., pp. 59-77, Springer, Dordrecht, The Netherlands, 2008. 

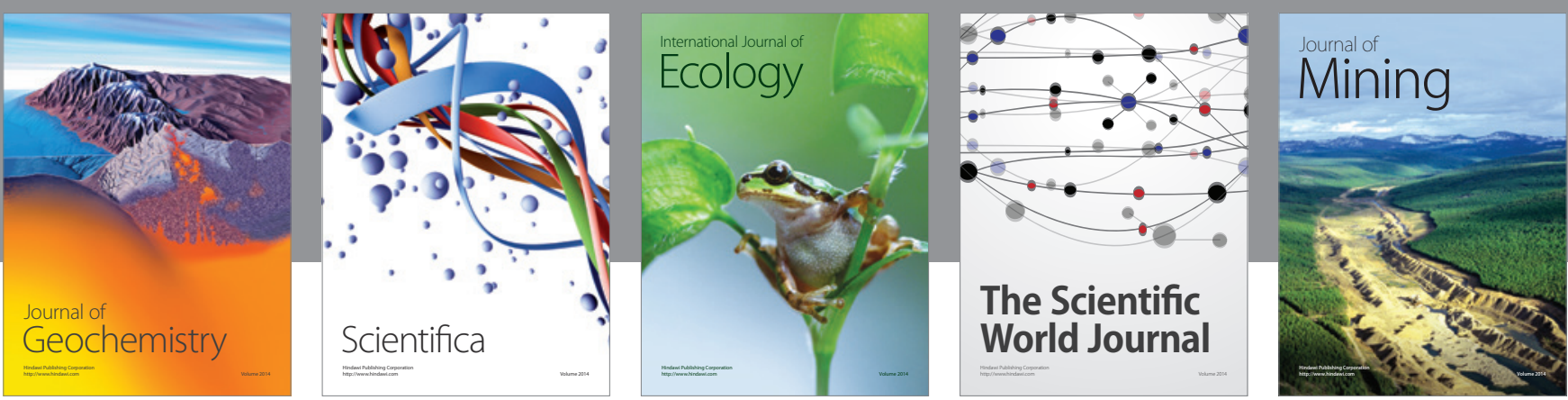

The Scientific World Journal
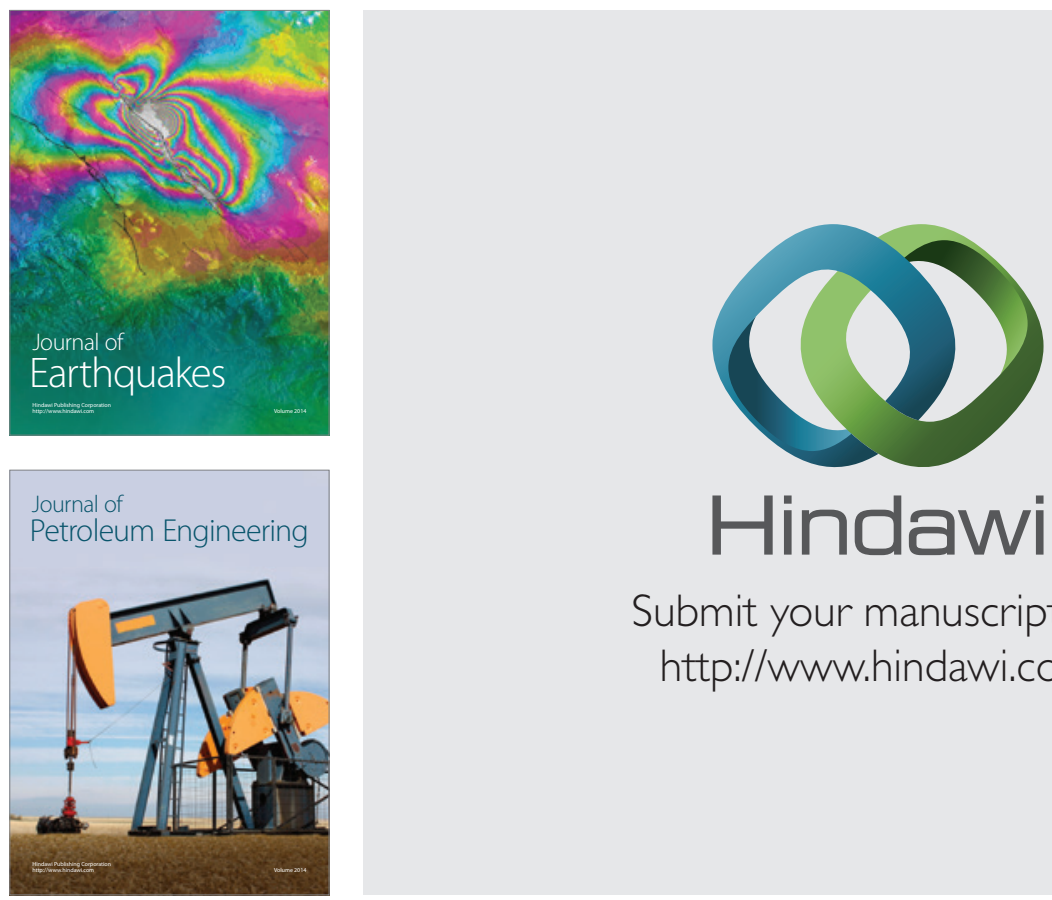

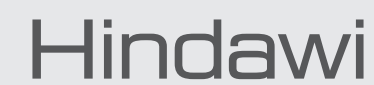

Submit your manuscripts at

http://www.hindawi.com
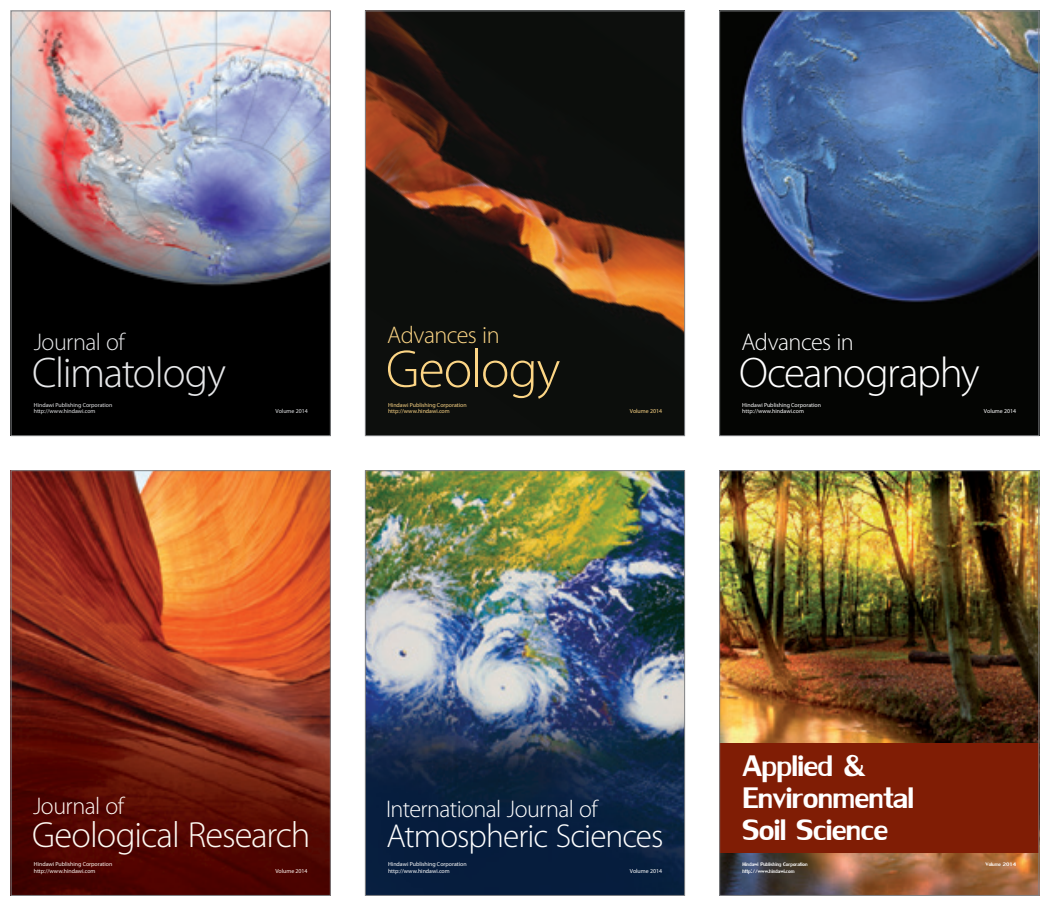
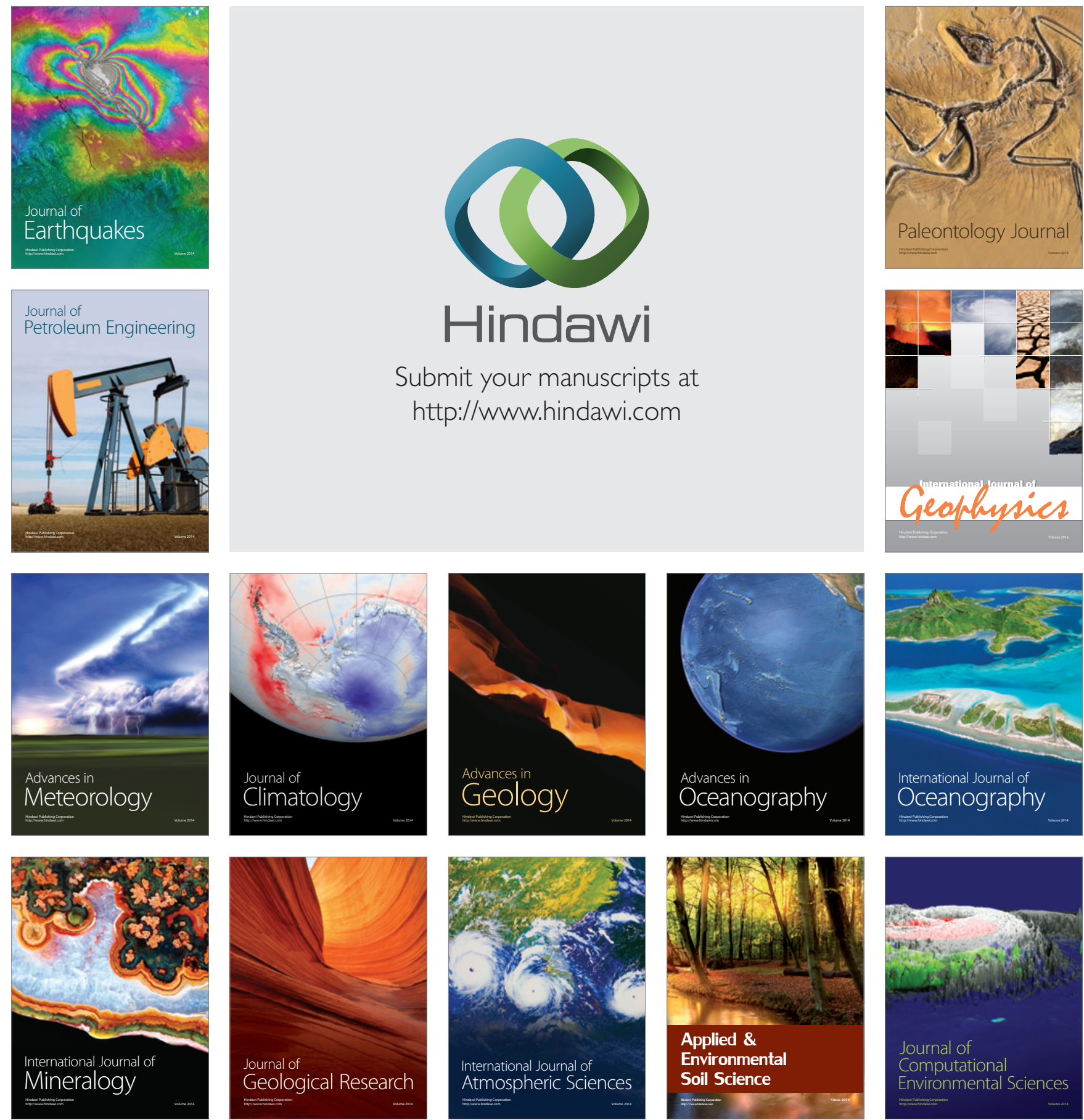